\title{
System optimization of innovative tri-generation system for distributed power application
}

\author{
T.T. Chow ${ }^{1, *}$, Guangya Zhu ${ }^{1,2}$, and C.K. Lee ${ }^{1}$ \\ ${ }^{1}$ Division of Building Science and Technology, City University of Hong Kong, Hong Kong SAR, China \\ ${ }^{2}$ Department of Architecture and Civil Engineering, City University of Hong Kong, Hong Kong SAR, China
}

\begin{abstract}
The building sector is one major primary energy consumer and pollutant emission source. In recent years, the building-related research studies on the potential use of Maisotsenko-cycle in energy systems have been increasing in recent years. The growing interest lies in its expanded applications beyond the air-conditioning systems (the main "energy consumers" in buildings) into the prime movers (the key players in power generation). In order to evaluate its application merits in the practical tri-generation system of the urban districts, an extensive computer simulation platform has been developed. Based on a case study, this paper describes the techniques in the mixed use of numerical tools in performing system optimization studies for distributed power application on a university campus site. The practicality of the methodology is demonstrated through a hypothetical tri-generation system primed with Maisotsenko combustion turbine cycle. The findings are very much interesting.
\end{abstract}

\section{Introduction}

In present days, thermal power plants are globally recognised as the major greenhouse gas (GHG) emission source. On the other hand, buildings consume more than $40 \%$ of the primary energy worldwide [1]. Apart from increasing the share of renewable energy outputs, which nevertheless are restricted by the concerns about economic returns as well as geographic limitations, the further enhancement of fuel energy extraction and distribution from the thermal power generation process is seen as another straightforward approach for solving the global environmental problems [2]. In essence, this can be readily achieved by making full use of the waste heat from the prime movers (PM's) to provide simultaneous heating and cooling, together with the electric power generation. According to the general practices in urban cities, the building electricity supply is from the utility grid, the space cooling is through the electricity-operated vapour-compression chiller system, whereas the space heating is served by fuel combustion or electric heaters. Hence a combined cooling, heating and power (CCHP) system, or the tri-generation so called, can be employed to serve the various building energy needs. There can be a variety of options, such as the use of thermally-driven absorption chillers as the space cooling source. By converting the fuel energy in a cascade manner through heat recovery in the trigeneration system, the overall energy utilization efficiency may reach $80 \%$ or higher. This is much attractive than the conventional thermal power plants. Moreover, a tremendous reduction in $\mathrm{GHG}$ emission can be achieved.
Although plenty of research articles on tri-generation technologies are currently available [3], the system design or synthesis remains an open applied-research issue. For example, most of the previous works reported on system design optimization were related to single building applications. In reality, this is unlikely to happen in large building developments. Indeed, the trigeneration application at the district scale can be more beneficial than at small building clusters, since the variety in daily or hourly CCHP demands across the building types $[4,5]$ can easily trim down the peak demand levels of the entire district. The electricity demand of an urban district is normally in the order of megawatts. The suitable PM's designed for such an operation scale are the gas turbine, steam turbine, or their combined cycles [6]. Among these options, the Maisotsenko combustion turbine cycle (MCTC), which is available as an advanced humidified gas turbine cycle, can offer higher electrical efficiency than the conventional simple gas turbine with recuperator (SGTR) [7]. So far the research on using MCTC as the $\mathrm{PM}$ in tri-generation was seldom conducted and reported. In particular, its benefits over the SGTR in term of simultaneous electricity generation and thermal energy recovery has not been adequately investigated. For these reasons, the development of an innovative MCTC-primed tri-generation system is introduced in this article. Its performance was then compared with another one primed by the conventional SGTR.

\footnotetext{
* Corresponding author: bsttchow@cityu.edu.hk
} 


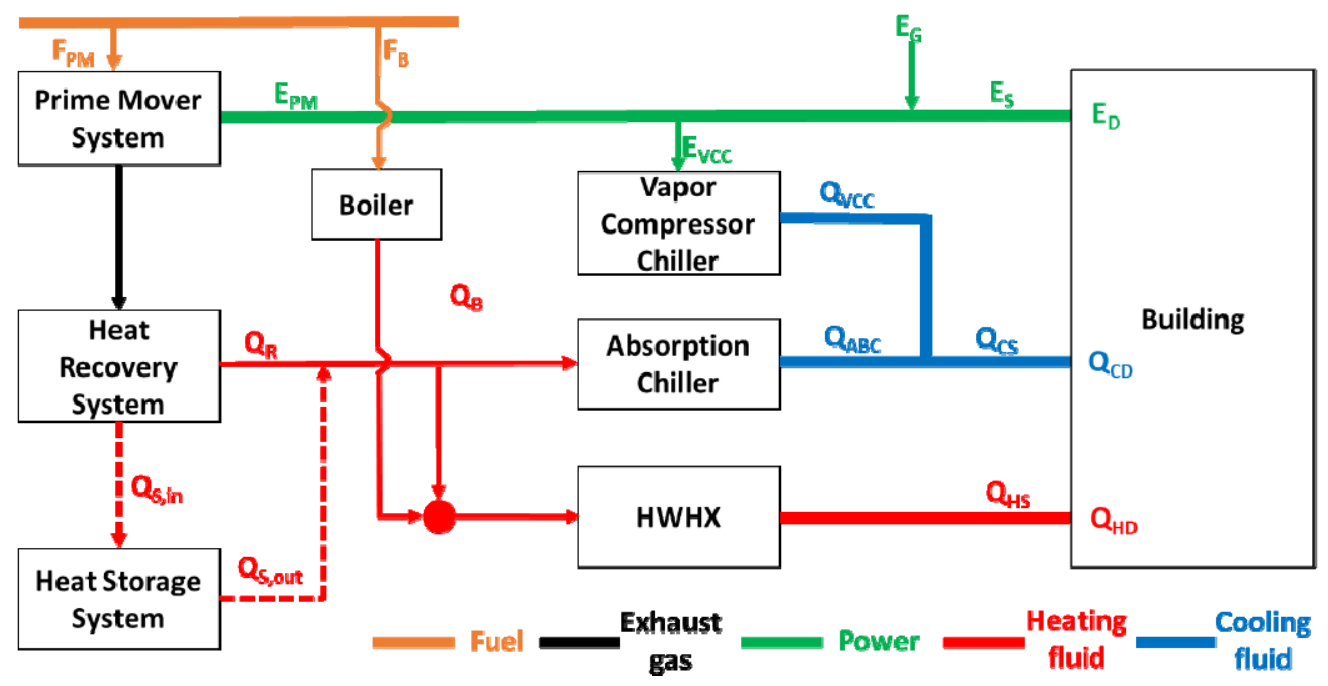

Fig. 1. The tri-generation system arrangement in this study.

Our self-developed numerical model was linked to the advanced simulation software for modelling the whole CCHP system and for further performance evaluation. The application potential of the proposed new tri-generation system was examined in the capital city of China, where substantial cooling and heating are required in the summer and winter seasons respectively.

\section{System description and formulation}

Fig. 1 shows the superstructure of the tri-generation system investigated in this study. The major equipment includes the MCTC (as the PM), the heat recovery and storage systems (HRS \& HSS), the gas-fired boiler, the vapor-compression and absorption chillers (VCC \& $\mathrm{ABC}$ ) and the hot water heat exchanger (HWHX) as well. The fuel energy input to the PM, as one key-player in power generation, is converted to electricity plus the waste heat (unused). In case the electrical output from the PM is unable to fulfil the overall instantaneous building demand, auxiliary supply from the utility grid is then required. The HRS recovers the unused heat from the PM. Together with the auxiliary heat supply from the boiler (and through the HWHX), the building thermal demand (including space heating/cooling and domestic hot water) can be met. In the current study, the following-electrical-load strategy was adopted in the CCHP design. So the provision of electrical storage is not required. To optimize the utilization of recovered heat and to minimize the frequency of boiler operation, the HSS serves as a buffer to handle the unbalance in energy supply and demand. Meanwhile space cooling is handled by the fleet of $\mathrm{ABC}$ and $\mathrm{VCC}$, with the priority given to the $\mathrm{ABC}$ service.

To examine the year-round performance of this complex CCHP system, TRNSYS as a component-based dynamic simulation software was employed as the analytical tool. Suitable component models can be directly selected from the TRNSYS library, like the VCC, ABC, HWHX, boiler, building zone, etc. to build the complete system model through a graphical interface. The PM, modelled as the performance data file generated from the parametric model, was used to determine the equipment output through a multidimensional linear interpolation algorithm.

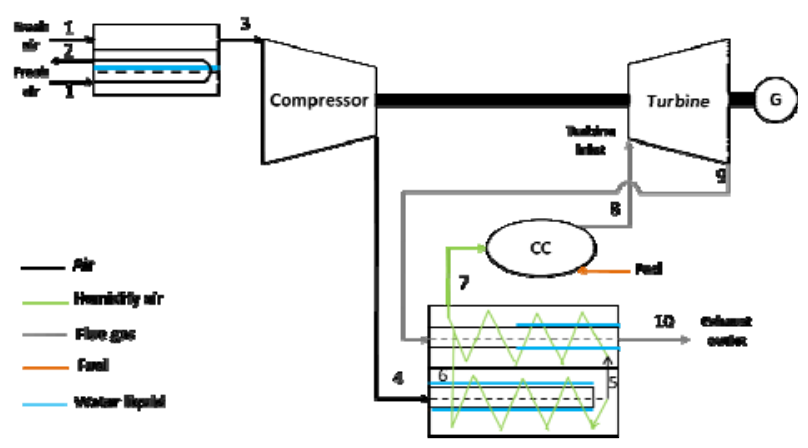

(a) MCTC

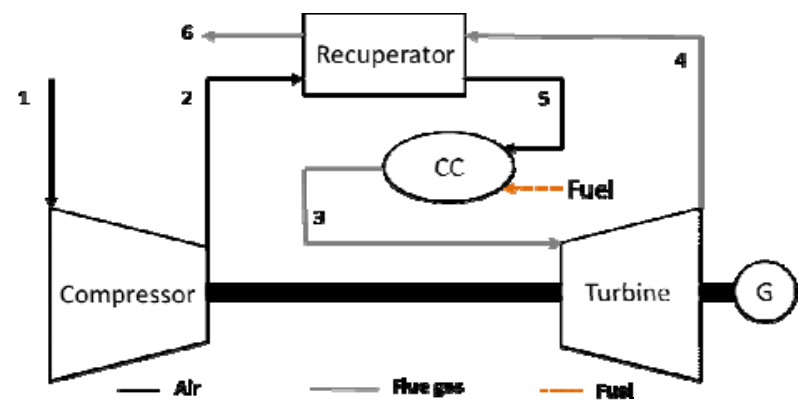

(b) SGTR

Fig. 2. Alternative PM arrangement schemes.

Fig. 2 shows the schematic arrangements of the two alternative PM's. For the MCTC shown in Fig. 2(a), an inlet Maisotsenko cycle evaporative cooler is used to pre-cool the fresh air ' 1 ' that enters the compressor. Between the compressor and the combustion chamber, there is an air saturator consisted of two parts: a regenerative Maisotsenko cycle (M-cycle) as the lower

\footnotetext{
*Corresponding author: bsttchow@cityu.edu.hk
} 
part and a conventional indirect evaporator cooler as the upper part. This serves to humidify and pre-heat the compressed air '4' using the hot exhaust gas ' 9 ' from the turbine. Regarding the SGTR in Fig. 2(b), the air saturator is simply replaced by a typical heat recuperator and no inlet M-cycle evaporative cooler will be provided.

To model the PM's, a constant-polytropic efficiency approach was adopted, as detailed in Fong and Lee [8]. The formulation of the air saturator was based on the works of Saghafifar and Gadalla [7], except that both the dew-point and wet-bulb effectiveness were calculated in this study (rather than using specific values). The details of the models of the heat recuperator, the combustion chamber as well as the complete cycle calculation can be found in Fong and Lee [8].

With the VCC model (Type 666) and the ABC model (Type 107), the respective chiller design capacities and their $C O P$ 's can be specified as the inputs. The off-design chiller performances were determined using the corresponding factors corrected for the capacity and energy inputs, with regard to the reference operating conditions from a TRNSYS data file. To calculate the partial-load performances, the respective part-load ratio $(P L R)$ characteristics were adopted based on the works of Luo and Fong [9], as shown in Fig. 3. According to Wang et al. [10], there is no need to consider the impact of capacity on the rated $C O P$.

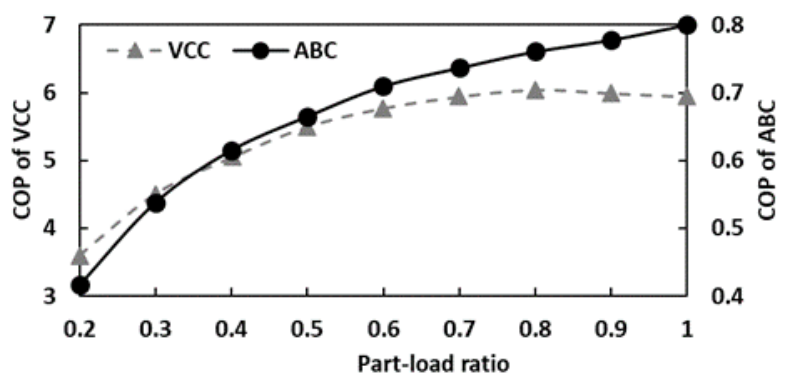

Fig. 3. Chiller part-load ratio characteristics.

Table 1. Results comparison on MCTC performance.

\begin{tabular}{|c|c|c|c|}
\hline Performance & Ref. [7] & $\begin{array}{c}\text { Current } \\
\text { model }\end{array}$ & $\begin{array}{c}\text { Error } \\
\text { (\%) }\end{array}$ \\
\hline $\begin{array}{c}\text { Mass flow rate at } \\
\text { compressor (kg/s) }\end{array}$ & 94.8 & 94.8 & 0 \\
\hline $\begin{array}{c}\text { Mass flow rate at turbine } \\
(\mathrm{kg} / \mathrm{s})\end{array}$ & 110.3 & 110.7 & 0.36 \\
\hline $\begin{array}{c}\text { Specific work input to } \\
\text { compressor (kJ/kg) }\end{array}$ & 375.3 & 384.7 & 2.50 \\
\hline $\begin{array}{c}\text { Specific work output } \\
\text { from turbine (kJ/kg) }\end{array}$ & 934.4 & 928.6 & 0.62 \\
\hline \begin{tabular}{c} 
Fuel injection rate (kg/s) \\
\hline $\begin{array}{c}\text { Exhaust gas temperature } \\
(\mathrm{K})\end{array}$
\end{tabular} & 2.2 & 2.3 & 4.55 \\
\hline Electrical efficiency (\%) & 47.4 & 47.2 & 0.42 \\
\hline
\end{tabular}

\section{Numerical analysis}

\subsection{MCTC model validation}

Prior to the start of system performance evaluation, the model of the MCTC has to be first validated. To achieve this, a reference case [7] from Saghafifar and Gadalla was chosen, and our simulated results based on the present model were compared with the published data. Accordingly, the comparison results are shown in Table 1. Good matching can be seen from the figures, in that the maximum error was below $5 \%$ for the case of fuel injection ratio, and below $1 \%$ for system electrical efficiency. Therefore, the validity of the present MCTC model was confirmed.

\subsection{System optimization method}

The target of the optimization analysis was to determine the capacity and quantity of each major component in the tri-generation system that would achieve the highest level of cost saving. In the process, the following information or parameters were made available:

(i) Various building energy demand profiles,

(ii) Energy cost schedules,

(iii) Year-round weather data,

(iv) Heat exchanger characteristics, and

(v) System initial and running costs.

Table 2. Parameters assigned for GA optimization.

\begin{tabular}{|c|c|}
\hline Algorithm parameter & Value \\
\hline Population size & 60 \\
\hline Number of generation cycles & 100 \\
\hline Chance of crossover & 0.7 \\
\hline Chance of mutation & 0.1 \\
\hline \multicolumn{2}{|l|}{ Search range } \\
\hline $\begin{array}{l}\text { Nominal power output of prime mover } \\
\qquad(\mathrm{kW})\end{array}$ & $2500-40000$ \\
\hline $\begin{array}{l}\text { Nominal capacity of absorption chiller } \\
\qquad(\mathrm{kW})\end{array}$ & $500-5000$ \\
\hline $\begin{array}{l}\text { Nominal capacity of vapor-compression } \\
\text { chiller }(\mathrm{kW})\end{array}$ & $5000-15000$ \\
\hline $\begin{array}{l}\text { Nominal capacity of hot storage system } \\
\qquad(\mathrm{kW})\end{array}$ & $5000-50000$ \\
\hline Number of absorption chiller & $0-10$ \\
\hline Number of vapor-compression chiller & $0-10$ \\
\hline
\end{tabular}




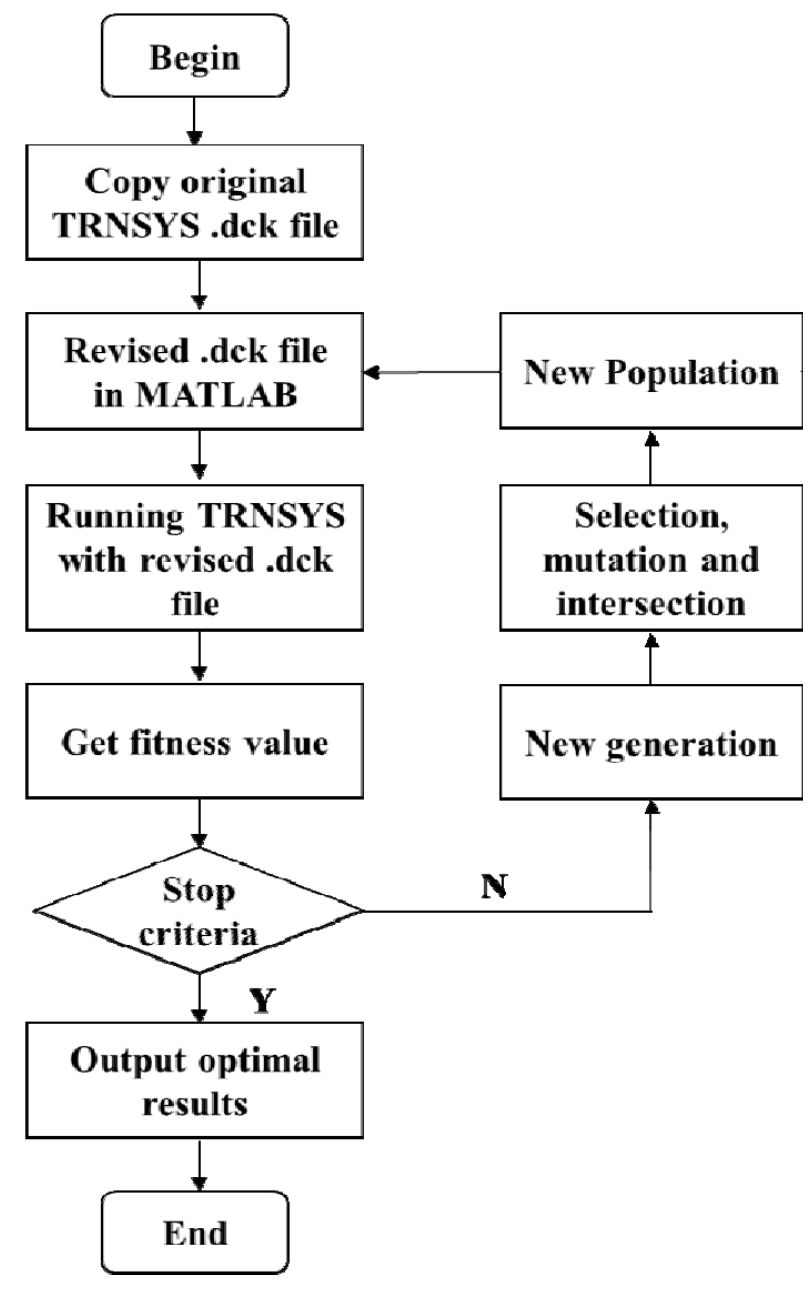

Fig. 4. Flow chart for the system optimization process.

The genetic algorithm (GA) method was employed for this optimization problem. GA is a stochastic method to search for the optimal point, which allows a more global solution to be obtained from the defined space, rather than being trapped in a local extremum.

The annual total cost saving ratio (ATCR) was the objective target in this optimization study. ATCR compares the annual total cost (ATC) of the new trigeneration scheme under the trial run with a conventional scheme. In this reference scheme, the building energy demands such as electricity, cooling and heating are covered by the utility grid, VCC and boiler respectively. To execute the optimization process as displayed in Fig. 4, two computer software: TRNSYS and MATLAB were used interactively.

MATLAB is a widely used programming platform developed by the MathWorks Company. It is a multiparadigm mathematical tool that allows for calculation through matrix manipulations. This is able to accelerate the calculation speed. The platform includes many toolboxes to help the users to plot data, implement special algorithms and create user interfaces [11]. TRNSYS is a simulation platform used in the fields of renewable energy engineering and building simulation [12]. The TRNSYS 17 with component library TESS was applied for equipment modelling, e.g. heat-driven absorption chiller sets, electricity-driven chiller sets, and the respective heat exchangers.

With the dynamic model of the complex system built in TRNSYS, the energy performance with different input data sets was computed. Then through the MATLAB multi-paradigm numerical computing platform, the optimization search based on GA was conducted with the renewed generation set as referenced in Table 2. In each trial, TRNSYS was called again in MATLAB to find the fitness value of the modified inputs. The process repeated until the stop criterion was met.

\subsection{Hypothetical case study}

In this study, a hypothetical case was created based on an existing university in operation in China. Fig. 5 shows the campus layout plan. Similar to many urban districts, the campus was composed of a mix of buildings that carry different functions and operating schedules. In our hypothetical case, these buildings were grouped into nine building categories. The hourly energy/load demand profile of each category was determined based on the following input data: (i) building geometry and façade details, (ii) building operation schedules brought into consideration the university semester and holiday periods, (iii) facility operation power requirement, and (iv) typical hourly weather data. Table 3 shows the external façade compositions and their physical properties. The building end-use included the lighting, air conditioning, lift and escalator, hot water usage, and miscellaneous equipment. The typical meteorological year (TMY) data of Beijing was used in this case study.

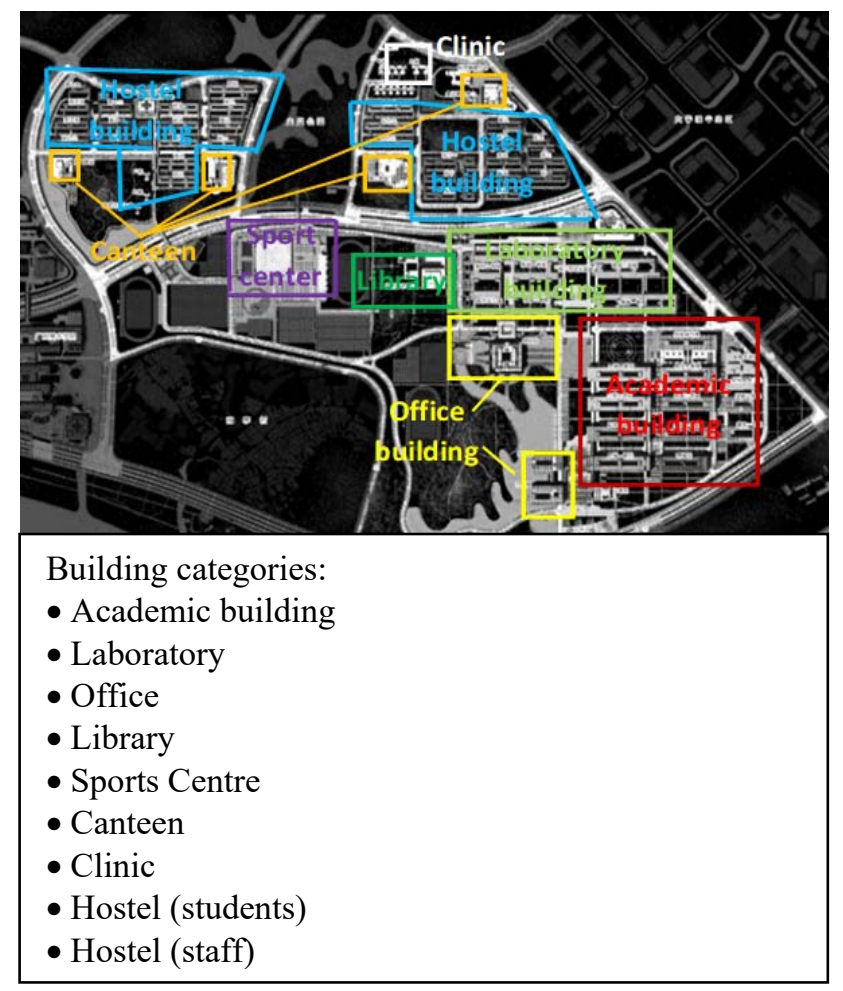

Fig. 5. University campus layout in the case study. 
Table 3. Building envelope composition and physical properties.

\begin{tabular}{|c|c|c|}
\hline Façade & Layers / properties & Input / value \\
\hline \multirow{5}{*}{$\begin{array}{c}\text { Vertical } \\
\text { Wall }\end{array}$} & Coating materials & $15 \mathrm{~mm}$ \\
\hline & Concrete & $290 \mathrm{~mm}$ \\
\hline & Foam insulator & $80 \mathrm{~mm}$ \\
\hline & Coating materials & $15 \mathrm{~mm}$ \\
\hline & U-value & $0.47 \mathrm{~W} /\left(\mathrm{m}^{2} \mathrm{~K}\right)$ \\
\hline \multirow{3}{*}{$\begin{array}{l}\text { Vertical } \\
\text { glazing }\end{array}$} & Type & Double glazing \\
\hline & g-value & 0.589 \\
\hline & U-value & $0.47 \mathrm{~W} /\left(\mathrm{m}^{2} \mathrm{~K}\right)$ \\
\hline \multirow{5}{*}{ Flat Roof } & Plaster board & $10 \mathrm{~mm}$ \\
\hline & Fiber glass & $112 \mathrm{~mm}$ \\
\hline & Roof deck & $19 \mathrm{~mm}$ \\
\hline & Foam insulator & $50 \mathrm{~mm}$ \\
\hline & U-value & $0.226 \mathrm{~W} /\left(\mathrm{m}^{2} \mathrm{~K}\right)$ \\
\hline
\end{tabular}

The complex model of the campus-buildings was developed through the building component Type 56. From the computational results, the peak electricity demand was 16.6 MW, with the air-conditioning load excluded. The peak cooling demand of the entire campus was 85.2 MW, and the peak hot water demand (that caters for both space heating and domestic hot water needs) was 134.4 MW.

\section{Results analysis}

From the hourly simulation results, the energy demands of the two tri-generation systems were found fluctuating across the days and seasons. With the large equipment capacities in the system design, both the MCTC and SGTR options were able to meet the campus demands easily. Table 4 shows the optimization results considering all cases. It can be seen that the total optimal PM capacities were significantly lower than the peak power demands (of which the building electrical loads included those of the VCC from the supply side). The reason was that within a year the peak demand occurred only within a short time duration. Hence, it would not be cost effective if the PM's had to be operating under an unfavourably low part-load ratio most of the time, considering the burden on both the initial and operating costs. On the other hand, the optimal capacity of the MCTC was higher than that of the SGTR. This is because the electricity generation efficiency and the partload performance of the MCTC-primed case were better than those of the SGTR-primed case.

Table 4. Optimization results for the two CCHP options.

\begin{tabular}{|c|c|c|}
\hline Design parameter & $\begin{array}{c}\text { MCTC- } \\
\text { primed } \\
\text { CCHP }\end{array}$ & $\begin{array}{c}\text { SGTR- } \\
\text { primed } \\
\text { CCHP }\end{array}$ \\
\hline $\begin{array}{c}\text { Nominal power output of PM } \\
(\mathrm{kW})\end{array}$ & 18,358 & 17,177 \\
\hline Nominal capacity of ABC (kW) & 1,824 & 1,985 \\
\hline Nominal capacity of VCC $(\mathrm{kW})$ & 15,255 & 18,920 \\
\hline Nominal capacity of $\mathrm{HSS}(\mathrm{kW})$ & 21,005 & 19,790 \\
\hline Total number of ABC & 5 & 5 \\
\hline Total number of VCC & 5 & 4 \\
\hline ATCR $(\%)$ & 34.86 & 37.34 \\
\hline
\end{tabular}

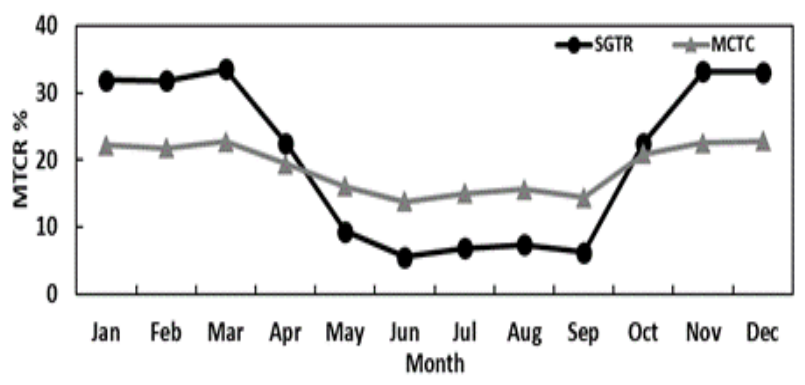

Fig. 5. Profiles of monthly-total cost saving ratio: SGTR vs MCTC.

From Table 4, the optimal ATCR for the SGTR case was higher than the MCTC case. The situation was not the same when the MCTC and SGTR were solely used for power generation, as reported by the previous researchers [7]. This can be explained by comparing the year-round profiles of the monthly-total cost saving ratio (MTCR) of the two CCHP systems shown in Fig. 5. Here, the MCTC-primed CCHP system yielded higher cost savings in summer (between May and September inclusive) but lower savings for the rest of the year as compared to the SGTR-primed case. Clearly, the economic benefits of recovering unused energy for heating were much more significant than those for cooling when considering the large gap in COP between $\mathrm{VCC}$ and $\mathrm{ABC}$ under normal operation. With the continental climate around this study case, the recovered 
waste heat generally could not meet the substantial heating demand in winter. The HSS was seldom in service during the said period. On the contrary, with a lower electrical efficiency of the SCTR, more waste heat was available. This led to a better performance of the SGTR-primed CCHP system as compared to the MCTCprimed case.

Tri-generation as a distributed power technology is still an open topic among the engineers, researchers and policymakers. There are many opportunities for them to work together, and make it more advanced in terms of energy saving, environment preservation, and/or cost reduction. For instance, the integration with renewable energy sources could further improve its sustainability performance. This is not limited to the applications of solar or wind power but also the trials on biofuels. We would suggest more test cases to be included on a board and forward-looking manner. For the smart cities in the near future, the changing urban design, electric vehicle applications and low-carbon living style will change the load profiles of the building mix at the district level. The benefits of the proposed tri-generation system would be more transparent through additional computation analysis and field work evaluation.

\section{Conclusion}

This paper presented a design optimization study of a district-scale tri-generation system using genetic algorithm. Two prime mover cases were evaluated, namely the MCTC (Maisotsenko combustion turbine cycle) and the SGTR (simple gas turbine with recuperator) options. Cost saving was taken as the optimizing target of these distributed power schemes. The CCHP simulation model was first developed and the accuracy validated by published data.

A hypothetical case study based on Beijing was introduced using a university campus with a mix of building types. The capital city is having high heating and cooling demands across the seasons. Based on the typical weather data, simulation runs were conducted successfully with the interactive use of the advanced thermal simulation program TRNSYS and the multiparadigm computing tool MATLAB.

The energy performance from computer simulation showed that the conventional SGTR-primed CCHP system is financially more attractive than the innovative approach based on the MCTC technology. This finding was different from the case when the same two options were used in a thermal power plant and solely for electricity generation. Further evaluation found that the less satisfactory outcome was probably reflecting the huge heating demand in winter in favour of the sole operation mode. Hence this concludes that the complex system application requires careful evaluation case by case.

Overall speaking, the numerical analysis supports the CCHP distributed power installation at the urban district level. The tri-generation scheme with gas turbine can offer significant financial and environmental benefits, that help to relieve the global fuel shortage, energy wastage, and climate change problems that are threatening our planet.

This work was funded by the research projects 9231136 and 9678154 from the City University of Hong Kong.

\section{References}

1. IEA. Energy Efficiency 2017 https:/www.iea.org/publications/freepublications/pu blication/Energy_Efficiency_2017.pdf

2. A.N. Unal, S. Ercan, G. Kayakutlu, Int. J. Energy Res. 39, 1311 (2015)

3. Q.N. Chu, X.L. Luo, B.J. Zhang, Y. Chen, Energy Convers. Manage. 133, 385 (2017)

4. S. Bracco, G. Dentici, S. Siri, Energy 55, 1014 (2013)

5. A. Omu, R. Choudhary, A. Boies, Energy Policy 61, 249 (2008)

6. F.A. Al-Sulaiman, F. Hamdullahpur, I. Dincer, Int. J. Energy Res. 35, 233 (2011)

7. M. Saghafifar, M. Gadalla, Appl. Energy 149, 338 (2015)

8. K.F. Fong, C.K. Lee, Build Simul 10, 509 (2017)

9. X.J. Luo, K.F. Fong, Energy Convers. Manage. 154, 538 (2017)

10. J. Wang, J. Wu, C. Zheng, Energy Build. 72, 353 (2014)

11. MATLAB,https://www.mathworks.com/help/pdf_d oc/matlab/getstart.pdf.

12. TRNSYS. TRNSYS 17, a Transient System simulation program. The Solar Energy Laboratory, University of Wisconsin-Madison (2011). 